\title{
Methyl Cholate and Resorcinarene New Carriers for the Recovery of Cr(III) Ions by Supported Liquid Membranes (SLM)s
}

\author{
Abdelkhalek Benjjar ${ }^{1,2^{*}}$, Tarik Eljaddi ${ }^{1}$, Oussama Kamal ${ }^{1,2}$, Laurent Lebrun ${ }^{2}$, Miloudi Hlaibi ${ }^{1,2}$ \\ ${ }^{1}$ Laboratoire Interface Matériaux et Environnement (LIME), Faculté des Sciences Aïn Chock, \\ Université Hassan II, Casablanca, Maroc \\ ${ }^{2}$ Laboratoire des Polymères, Biopolymères, Surfaces, UMR 6270 du CNRS, Faculté des Sciences et Techniques, \\ Université de Rouen, Mont-Saint-Aignan, France \\ Email: *Abdelkhalek.benjar@gmail.com
}

Received October 10, 2012; revised January 14, 2013; accepted February 10, 2013

Copyright (C) 2013 Abdelkhalek Benjjar et al. This is an open access article distributed under the Creative Commons Attribution License, which permits unrestricted use, distribution, and reproduction in any medium, provided the original work is properly cited.

\begin{abstract}
The technique of supported liquid membranes was used to achieve the facilitated transport of $\mathrm{Cr}(\mathrm{III})$ ions, using tow amphiphilic carriers, the methyl cholate and resorcinarene. For prepared SLMs, toluene as organic phase and film of polyvinylidene difluoride, as hydrophobic polymer support with $100 \mu \mathrm{m}$ in thickness and $0.45 \mu \mathrm{m}$ as the diameter of the pores. The macroscopic parameters ( $P$ and $J_{0}$ ) on the transport of these ions were determined for different medium temperatures. For these different environments, the prepared SLMs were highly permeable and a clear evolution of these parameters was observed. The parameter $J_{0}$ depended on the temperature according to the Arrhenius equation. The activation parameters, $E a, \Delta H^{\ddagger}$ and $\Delta S^{\ddagger}$, for the transition state on the reaction of complex formation $(S T)$, were determined. To explain these results for this phenomenon, and achieve a better extraction of the substrate, a model based on the substrate complexation by the carrier and the diffusion of the formed complex $(S T)$ was developed. The experimental results verify this model and determine the microscopic parameters $\left(K_{a s s}\right.$ and $\left.D^{*}\right)$. These studies show that these parameters $K_{a s s}$ and $D^{*}$ are specific to facilitated transport of $\mathrm{Cr}(\mathrm{III})$ ions by each of the carriers and they are changing significantly with temperature.
\end{abstract}

Keywords: Supported Liquid Membrane; Facilitated Transport; Methyl Cholate; Resorcinarene Permeability; Flux; Association Constant; Diffusion Coefficient

\section{Introduction}

Currently, different membrane types are used for many industrial applications, to recover or separate the constituents of a mixture, or to selectively control the exchange of material between different media. The use of membrane technology has in recent years a rapid growth, particularly because of the increasing application areas. This development should be increased because of the good performance offered by membrane processes and due to the emerging needs of environmental protection (effluent treatment, clean processes...). Meanwhile, these different applications, research increasingly pushed to better understand the functioning of these membrane processes, create more efficient or more specific, and

"Corresponding author. develop new methods to access new applications [1-6].

Today, it is necessary and certainly required to develop highly selective systems that are essential to consider the realization of separations and recoveries of metal ions very harmful to the environment from complex aqueous mixtures. For this purpose, the liquid-liquid separation technique is first widely used, with more or less suitable agents, for the recovery of metal ions from complex and loaded aqueous media. This technique involves the use of complexing agents and large amounts of organic solvents which are often expensive and toxic. It includes an extracting step by phase transfer, followed by back extraction step, two steps are enough consumers of organic solvents, particularly when volatile solvents. A stylish alternative to liquid-liquid extraction is the development of artificial membrane systems that mimic the 
process of facilitated transport across bio-membranes (by mobile carriers and more by ion channels).

Liquid membranes incorporating specific complexing agents are artificial systems of choice for the treatment of liquid media charged with metal ions. Of these membranes, supported liquid membranes (SLM)s are the most frequently used systems for these applications; these systems are developed from an inert polymer support. Indeed, the organic solution containing a specific complexing molecule is often incorporated by impregnation of this polymer support. Polypropylene is the most widely used polymer support due to its high porosity, which generates the best metal ions flux through the prepared SLMs. The supported liquid membrane process, have several advantages compared to liquid-liquid extraction. There are much less consumers of organic solvents, which is an important criterion in respect of the environmental protection constraints and containment of toxic releases. These processes enable continuous operation in one step, since the two steps of extraction and stripping are so coupled to the two interfaces. Indeed, the membranes are thin films that separate two fluids; an essential property of membranes is their permeability $(P)$, the ability to allow passage of only certain species from one medium to another, while acting as a barrier to other species. For this work, we try to develop a simple and effective technique for extracting $\mathrm{Cr}$ (III) ions from acidic media. This technique is based on a series of works performed on different membrane transport phenomena, such as facilitated transport of metal ions or organic molecules across membranes, using suitable agent carriers.

Our work will be limited to the supported liquid membrane (SLM)s, made of a polymer film, inert, microporous polyvinylidene difluoride (PVDF), a thickness of 100 $\mu \mathrm{m}$ and $69 \%$ porosity with pores of $0.45 \mu \mathrm{m}$ in diameter, containing one of the following amphiphilic carriers: Methyl Cholate or Resorcinarene (Figure 1), soluble in toluene phase [7-10]. A kinetic model as well as a transport mechanism has been developed and tested for the facilitated transport of $\mathrm{Cr}$ (III) ions from different solutions. The macroscopic parameters, permeabilities $P$ and initial fluxes $J_{0}$ are determined and related to microscopic parameters, association constant $K_{a s s}$, and apparent diffusion coefficient $D^{*}$, relating to the stability of the complex (Carrier-Substrate) formed at the membrane interface, and its diffusion through the (SLM)s organic phase. Detailed studies on the influence of temperature are performed; the results clearly show that these macroscopic and microscopic parameters vary depending on the medium temperature. An increase in temperature allows obtaining larger, permeabilities, initial fluxes and apparent diffusion coefficients, therefore, highly permeable membranes with a more efficient extraction of trans-

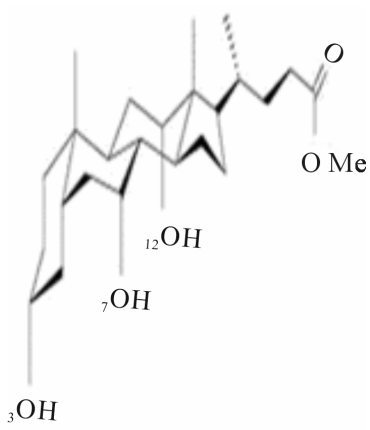

(a)

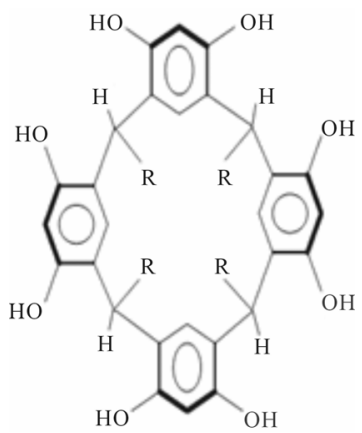

(b)
Figure 1. Structures of carriers: (a) Methyl cholate; (b) Resorcinarene $\left(\mathrm{R}=\mathrm{CH}_{3}\left(\mathrm{CH}_{2}\right)_{10}\right)$.

ported substrate, and low stability complexes with small values for the association constants (Carrier-Substrate). These results are important and will determine the movement nature of $\mathrm{Cr}$ (III) ions through SLM organic phase and explain the high permeability of such membranes for facilitated transport of these metal ions.

\section{Description and Operating Principle of the (SLM)s}

The supported liquid membranes (SLM)s, is made of an organic solvent, immobilized by capillary forces in the pores of a micro porous support, separating the source phase to receiving phase. The support of these membranes is generally an hydrophobic microporous inert polymer, which is characterized by a low thickness of about 25 to $100 \mu \mathrm{m}$ and pore diameter from 0.12 to $1 \mu \mathrm{m}$ $[11,12]$. Since the chemical species passage through this membranes type is an interfacial phenomenon, the use of a support with high porosity is necessary to increase the contact area and the selectivity to the passage of species, and therefore able to ensure the best transport and separation conditions through these membranes (SLM)s [13]. To improve the separation process, the researchers added to the SLM organic phase, mobile carriers to accelerate and facilitate the transport of species, while increasing the selectivity of the membranes $[5,14]$. The SLM technique is an approach widely used for the extraction and enrichment of metal ions and organic compounds [15-17]. Indeed, this technique has been used to study the transport and apply it to the selective extraction and enrichment of varied organic compounds, such as amino acids $[18,19]$, the aromatic aminophosphates [20], sugars [21$23]$, herbicides [24,25] and some organic acids [26,27]. This method which is called facilitated transport through supported liquid membranes is based on the recognition of a substance $(S)$ by a carrier molecule $(T)$. This process involves mobility within the membrane of a complex $(S T)$ produced by a reversible forming reac- 
tion between the carrier $(T)$ and transported species $(S)$, at the membrane interfaces with the source and receiving phases. This phenomenon of facilitated transport through the (SLM)s is a cyclical process that involves five consecutive steps:

1) Diffusion of free substrate $(S)$ in the source phase to the membrane interface.

2) Formation of the complex substrate-carrier $(S T)$ at the membrane interface with the source phase.

3) Diffusion of the complex (ST) through the membrane organic phase to the membrane interface with the receiving phase.

4) Dissociation of the complex $(S T)$ at the membrane interface with the receiving phase.

5) Diffusion of free substrate $(S)$ in the receiving phase and the carrier $(T)$ in the membrane organic phase to resume a new cycle (complexation-diffusiondissociation).

These five steps represent the mechanism of facilitated transport through a SLM, with the diffusion step of the substrate-carrier complex (3), as the rate-determining step.

\section{Experimental and Theoretical Models}

\subsection{Transport Cell}

The transport experiments were performed in the cell represented by the diagram in Figure 2. This cell consists of two glass compartments, with a volume of $175 \mathrm{ml}$ each, separated by the micro porous membrane $(M)$. The cell is immersed in a thermostatic bath $(T B)$. A multistirrer $(M S)$ ensures the agitation of the two compartment solutions.

\subsection{Determination of the Macroscopic Parameters: Permeability $P$ and Flux $J$}

The membrane is placed between two compartments of the cell, a known volume of the substrate $\mathrm{S}$ solution with an initial concentration $C_{0}$, is introduced into the source compartment and placing the same water volume in the receiving phase compartment. We made several samples in the receiving phase in known time intervals. $C_{r}$ is the substrate concentration in the receiving phase at time $t$,

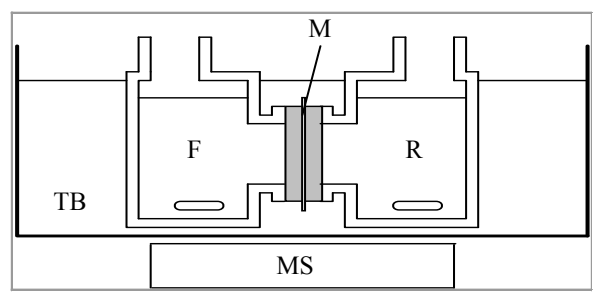

Figure 2. The cell for the facilitated transport through a SLM M: SLM. F: feed phase. R: receiving phase. TB: thermostatic bath. MS: multi-magnetic stirrer. the concentration of substrate in the source phase at this time is $C_{s}=C_{0}-C_{r}$. The equation that relates the flux $J$ to $C_{r}$ concentration of substrate $S$ is given by the relationship:

$$
\mathrm{d} C r / \mathrm{d} t=J \times S / V
$$

$S$ the membrane surface in contact with the source phase solution, $V$ the receiving phase volume. For a quasi-static state, the flux is related to the difference in concentrations of the two compartments $\Delta C=C_{s}-C_{r}$. by Fick's first law:

$$
J=P \times \Delta C / l
$$

$P$ membrane permeability and $l$ is the membrane thickness.

Since $C_{s}=C_{0}-C_{r}$, so

$$
\Delta C=C_{s}-C_{r}=C_{0}-2 C_{r}
$$

The combination of Equations (1)-(3), can find the following relationship:

$$
P \mathrm{~d} t=(l \times V / S) \mathrm{d} C_{r} /\left(C_{0}-2 C_{r}\right)
$$

After integration:

$$
P\left(t-t_{L}\right)=(l \times V / 2 S) \ln \left[C_{0} /\left(C_{0}-2 C_{r}\right)\right]
$$

This equation shows that after an induction period $\left(t_{L}\right)$, which can reach several hours, the term $-\operatorname{Ln}\left(C_{0}-2 C_{r}\right)$ must be a linear function of time $t$. The slope $(a)$ of the line $-\operatorname{Ln}\left(C_{0}-2 C_{r}\right)=f(t)$, calculates the permeability $P$ according to Equation (6).

$$
P=a \times V \times l / 2 S
$$

The initial flux $J_{0}$ can be calculated from the permeability $P$ by the following equation:

$$
J_{0}=P \times C_{0} / l
$$

The final state of the manipulation is a dynamic equilibrium established between the two compartments with $C_{s}=C_{r}=C_{0} / 2$ and equal diffusion rates in two opposite directions.

\subsection{Modelling and Calculations of Microscopic Parameters $K_{\text {ass }}$ and $D^{*}$}

The facilitated transport of substrate $\mathrm{S}$ depends on the formation and dissociation of the substrate-carrier complex $(T S)$ at the membrane-solution interfaces. The carrier $T$ is insoluble in the aqueous phase while the substrate $S$ is not soluble in the membrane organic phase. The complexation equilibrium in heterogeneous phases is written:

$$
S_{a q}+T_{o r g} \Leftrightarrow T S_{o r g}
$$

$o_{r g}$ and ${ }_{a q}$ represent respectively, the membrane organic phase and the aqueous solution of the feed phase. The complex concentration $[T S]_{i}$ at the interface of the 
membrane is given by law of mass action according to the equation:

$$
[T S]_{i}=K_{a s s} \times[T]_{i} \times[S]_{i}
$$

$K_{\text {ass }}$ is the association constant on the formation of the complex $(T S)$, this heterogeneous equilibrium constant is related to the complexation reaction at the interface membrane-feed phase.

$[T]_{i}$ : The carrier concentration at the interface of the membrane.

$[S]_{i}$ : The substrate concentration in the source phase at the interface of the membrane.

During the migration of complex $(T S)$ through the SLM organic phase (rate-determining step), the flux $J$ is determined by Equation (9), derived from Fick's first law, which assumes that the complex concentration is practically zero at the membrane-receiving phase interface (dissociation of complex).

$$
J=\left(D^{*} / l\right) \times[T S]
$$

$D^{*}$ is the apparent diffusion coefficient and $l$ is the membrane thickness. However, at the membrane-source phase interface, $[T S]_{i} \ll[S]_{i}$ (excess of substrate relative to the carrier) and the $[S]_{i}$ concentration is equal to the $[S]$, substrate concentration at time $t$ and thus $[S]_{i}=[S]_{t}$. The total $[T]_{0}$ concentration carrier immobilized in the membrane is constant, and at any time is equal to the sum of the concentrations $[T]_{i}$ and $[T S]_{i}$.

$$
[T]_{0}=[T]_{i}+[T S]_{i}=[T S]_{i} \times\left[\left(1+K_{a s s} \times[S]_{i}\right) / K_{a s s} \times[S]_{i}\right]
$$

$$
[T S]_{i}=[T]_{0} \times K_{a s s} \times[S]_{i} /\left(1+K_{a s s} \times[S]_{i}\right)
$$

Since, in the initial conditions operating with an excess of substrate relative to the carrier, and at the interface $[S]_{i}=[S]_{0}=C_{0}$ and $[T S]_{i} \approx[T]_{0}$. So the expression of the initial flux $J_{0}=\left(D^{*} / l\right) \times[T S]_{i}$ may be written in terms of concentrations $[T]_{0}$ and $C_{0}$, from Equations (9) and (11) according to the following terms:

$$
J_{0}=\left(D^{*} / l\right) \times\left[[T]_{0} \times K_{a s s} \times[S]_{i} /\left(1+K_{a s s} \times[S]_{i}\right)\right]
$$

or

$$
J_{0}=\left(D^{*} / l\right) \times\left[[T]_{0} \times K_{a s s} \times C_{0} /\left(1+K_{a s s} \times C_{0}\right)\right]
$$

This expression is used to calculate the permeability $P$ as a function $[T]_{0}, C_{0}$ concentrations, and $K_{a s s}$ association constant.

$$
P=J_{0} \times l / C_{0}=\left(D^{*}\right) \times\left[[T]_{0} \times K_{\text {ass }} /\left(1+K_{a s s} \times C_{0}\right)\right]
$$

We find that the macroscopic parameters $P$ and $J_{0}$ are proportional to the substrate initial concentration $C_{0}$, and have a Michaelis-Menten evolution, since for high substrate concentrations both parameters tend to limit values.
To determine the microscopic parameters $D^{*}$ and $K_{a s s}$, we use the method of Lineweaver-Burk to linearize the expression of Equation (12) according to Equation (14) and draw the right $1 / J_{0}=f\left(1 / C_{0}\right)$.

$$
1 / J_{0}=\left(l / D^{*}\right) \times\left[\left(1 /[T]_{0} \times K_{\text {ass }}\right) \times\left(1 / C_{0}\right)+\left(1 /[T]_{0}\right)\right]
$$

with:

$$
K_{a s s}=\operatorname{intercept}(O O) / \operatorname{slope}(P)
$$

and

$$
D^{*}=(l / O O) \times\left(1 /[T]_{0}\right)
$$

\subsection{Determination of Activation Parameters}

As the flux $J$ of the substrate $S$ through the SLM, is related to the change in the source phase $C_{r}$ concentration Equation (1), this parameter varies with temperature according to the Arrhenius relationship Equation (16) [2830]:

$$
J_{i}(T)=A_{j} \exp (-E a / R T)
$$

$R$ is the gas constant $\left(8.314 \mathrm{~J} \cdot \mathrm{mol}^{-1} \cdot \mathrm{K}^{-1}\right) . A_{j}$ a constant (preexponential factor) whose value is proportional to the number of favourable interaction faces between the substrate and carrier, and $E a$ is the transition state activation energy on the formation-dissociation reaction of complex $(S T)$ at the membrane interfaces and in the SLM organic phase.

After linearization we have:

$$
\ln J_{i}=(-E a / R T) \times 1 / T+\ln A_{j}
$$

From the slope of the line $\left(\ln J_{i}=f(1 / T)\right)$, we determine the $E a$ value. On the other hand, it is known from the activated complex theory [31,32]), that $E a$ is related to the activation enthalpy $\left(\Delta H^{\#}\right)$ by the relation:

$$
\Delta H^{\#}=E a-2500\left(\mathrm{~J} \cdot \mathrm{mol}^{-1}\right) \text { at } 298^{\circ} \mathrm{K}
$$

while the activation entropy $\left(\Delta S^{\#}\right)$, is related to $A_{j}$ constant by the equation:

$$
\Delta S^{\#}=R\left(\ln A_{j}-30.46\right)\left(\mathrm{J} \cdot \mathrm{mol}^{-1} \cdot \mathrm{K}^{-1}\right) \text { at } 298^{\circ} \mathrm{K}
$$

\section{Experimental Section}

All chemicals reagents and solvents used were pure commercial products of analytical grade (Aldrich, Fluka, Redel-Dehaene). The $\mathrm{Cr}$ (III) ions solutions used are obtained by hydrolysis of $\mathrm{Cr}\left(\mathrm{NO}_{3}\right)_{3}$ salt. The support is a micro porous polymer film, polyvinylidene difluoride (PVDF), a thickness of $100 \mu \mathrm{m}, 69 \%$ porosity and pore diameter is 0.45 microns. The membrane liquid solution consists of the organic phase toluene, containing $0.01 \mathrm{M}$ 
carrier concentration (Methyl Cholate or Resorcinarene). $\mathrm{Cr}$ (III) ions acidic solutions $(0.20-0.025 \mathrm{M})$ were prepared from a stock solution in doubly distilled pure water. After conditioning the prepared SLM [2,4,24], it is placed between two compartments of the transport cell (Figure 2), in the feed phase, the $\mathrm{Cr}$ (III) ions solution with known $C_{0}$ concentration, at $\mathrm{pH}=1,2$ or 3 and in the receiving phase $\mathrm{KNO}_{3}$ solution at $\mathrm{pH}=6$. Both phases are subject to the same agitation and the kinetic monitoring of $\mathrm{Cr}$ (III) ions transport occurs through regular withdrawals from the receiving phase in known time intervals. These samples were analyzed by UV-Visible spectrophotometer $\left(\lambda_{\max }=215 \mathrm{~nm}\right) . C_{r}$ concentrations of $\mathrm{Cr}$ (III) ions in the receiving phase are calculated, and the evolution of the term $-\operatorname{Ln}\left(C_{0}-2 C_{r}\right)$ versus time was studied. Table 1 represents an example of results on the $\mathrm{Cr}$ (III) ions transport from a source phase of $\mathrm{pH}=2(\mathrm{pH}$ is adjusted with nitric acid).

\section{Results and Discussion}

\subsection{Influence of the Source Phase Acidity}

Under the same experimental conditions, using the same SLM with the same carrier (Methyl Cholate), $\mathrm{Cr}$ (III) ions transport was performed at different $C_{0}$ concentrations of source phase, and for three different acidities, $\mathrm{pH}=1,2$ or $3\left(\mathrm{HNO}_{3}\right)$. The experimental results verify the kinetic proposed model for this facilitated transport type, and line segments represented by the graph of Figure 3 , which shows the linear evolution of $-\operatorname{Ln}\left(C_{0}-2 C_{r}\right)$ terms versus time, provided by this model.

The slopes calculated from these lines, according to the SLM to the transported substrate (Cr(III) ions), for Equation (6), allow determining the permeabilities $P$ of the different studied solutions, while the $\mathrm{Cr}$ (III) ions initial flux $J_{0}$ through this SLM are calculated using Equation (7). Studies conducted for the facilitated transport of $\mathrm{Cr}$ (III) ions, to the three acidity $\mathrm{pH}=1,2$ and 3 , were used to determine the results grouped in Table 2 .

Table 1. Facilitated transport example of Cr(III) ions.

\begin{tabular}{cccc}
\hline Time $(\mathbf{m i n})$ & Absorbance & $\boldsymbol{C}_{\boldsymbol{r}}(\mathbf{M})$ & $-\mathbf{L n}\left(\boldsymbol{C}_{\mathbf{0}}-\mathbf{2} \boldsymbol{C}_{\boldsymbol{r}}\right)$ \\
\hline 30 & 0.020 & 0.0107 & 2.542 \\
60 & 0.025 & 0.0133 & 2.611 \\
90 & 0.030 & 0.0160 & 2.687 \\
120 & 0.035 & 0.0186 & 2.769 \\
150 & 0.040 & 0.0213 & 2.857 \\
\hline
\end{tabular}

$C_{0}=\left[\mathrm{Cr}^{3+}\right]_{0}=0.10 \mathrm{M}, \mathrm{pH}=2,[M C]=0.01 \mathrm{M} \quad$ and $T=298^{\circ} \mathrm{K}$.
Table 2. Influence of the source phase acidity on the macroscopic parameters $P$ and $J_{0}$.

\begin{tabular}{|c|c|c|c|}
\hline$p H$ & $C_{0}=\left[\mathbf{C r}^{3+}\right]_{0} \mathbf{M}$ & $10^{7} \times P\left(\mathrm{~cm}^{2} \cdot \mathrm{s}^{-1}\right)$ & $\begin{array}{c}10^{5} \times J_{0} \\
\left(\mathrm{mmol} \cdot \mathrm{cm}^{-2} \cdot \mathrm{s}^{-1}\right)\end{array}$ \\
\hline \multirow{3}{*}{1} & 0.20 & 14.875 & 2.975 \\
\hline & 0.10 & 17.281 & 1.728 \\
\hline & 0.05 & 20.854 & 1.042 \\
\hline \multirow{3}{*}{2} & 0.20 & 16.916 & 3.383 \\
\hline & 0.10 & 19.468 & 1.946 \\
\hline & 0.05 & 22.166 & 1.108 \\
\hline \multirow{3}{*}{3} & 0.20 & 19.760 & 3.952 \\
\hline & 0.10 & 24.427 & 2.442 \\
\hline & 0.05 & 25.958 & 1.297 \\
\hline
\end{tabular}

$[M C]=0.01 \mathrm{M}$, toluene phase and $T=298^{\circ} \mathrm{K}$.

These results clearly show that the permeability parameter $P$ of the SLM varies inversely with the $\mathrm{Cr}$ (III) ions concentration, and an increase in substrate concentration causes a decrease in this parameter. However, the $\mathrm{Cr}(\mathrm{III})$ ions initial flux $J_{0}$ through SLM increases with the $C_{0}$ concentration of the substrate in feed phase [23, 24]. To verify the proposed mechanism for the facilitated transport of $\mathrm{Cr}$ (III) ions, and to determine the parameters $K_{\text {ass }}$ and $D^{*}$, according to the Lineweaver-Burk method we have drawn the lines $1 / J_{0}=f\left(1 / C_{0}\right)$, provided by Equation (14). For the three studied acidity, the obtained straight segments are represented by the graph in Figure 4.

The linearity of the functions $1 / J_{0}=f\left(1 / C_{0}\right)$ (Figure 4), clearly indicates that the proposed mechanism is verified, the interaction Substrate-Carrier allows the formation of a complex $(S T)$ with the (1/1) composition, in the SLM organic phase, and the migration of this complex through this phase is the rate-determining step of the mechanism for $\mathrm{Cr}$ (III) ions facilitated transport. From these line segments (Figure 4), slopes $(p)$ and intercepts $(O O)$ were calculated and using the expressions of Equation (15), the apparent coefficients $D^{*}$ and the association constants $K_{\text {ass }}$ were determined. The obtained results summarized in Table 3, show that these microscopic parameters $D^{*}$ and $K_{\text {ass }}$ vary with the medium acidity, the formed complex $(S T)$ is of low stability, while its diffusion through the SLM organic phase is important, and the apparent coefficient $D^{*}$ varies inversely with the association constant $K_{\text {ass }}$.

Various studies show that the characteristics nature and structure of the carrier are two important and decisive factors for the facilitated transport of metal ions and organic molecules through the (SLM)s [6,23,24,33,34)]. To complement our results, and examine the influence of the carrier nature, we conducted the same experiments under the same conditions with a new SLM containing Resorcinarene as carrier. The kinetic model and the 


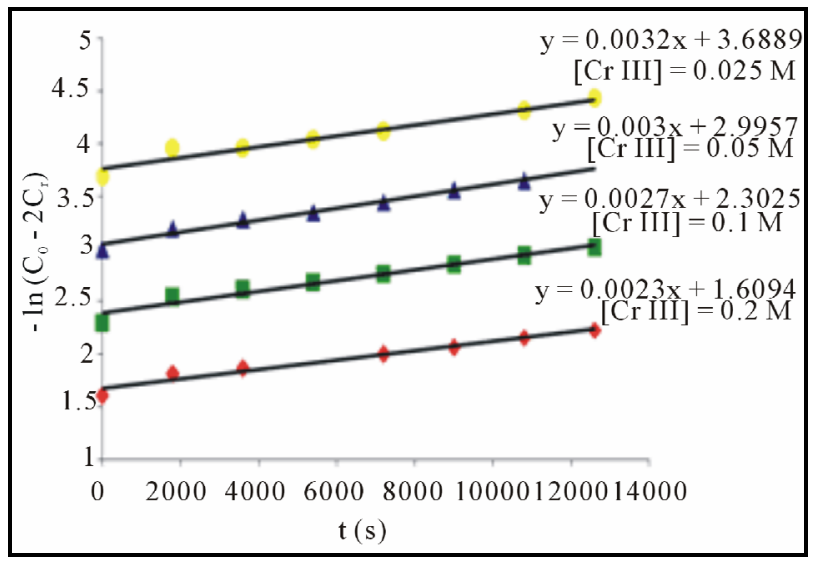

Figure 3. $-\operatorname{Ln}\left(C_{0}-2 C_{r}\right)$ functions evolution versus time for $\mathrm{Cr}(\mathrm{III})$ ions facilitated transport at different $C_{\mathbf{0}}$ concentrations, $[M C]=0.01 \mathrm{M}, \mathbf{p H}=\mathbf{2}$ and $T=298^{\circ} \mathrm{K}$.

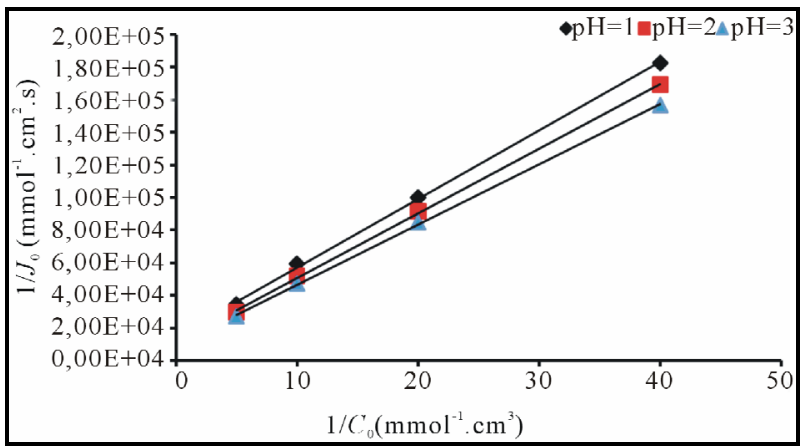

Figure 4. The Lineweaver-Burk plots for the facilitated transport of $\mathrm{Cr}^{3+}$ ions through the used SLM. $[\mathrm{MC}]=0.01 \mathrm{M}$, toluene phase and $T=298^{\circ} \mathrm{K}$.

Table 3. The source phase acidity influence on the parameters $D^{*}$ and $K_{\text {ass. }}$.

\begin{tabular}{ccc}
\hline $\mathrm{pH}$ & $K_{\text {ass }}\left(\mathrm{L} \cdot \mathrm{mol}^{-1}\right)$ & $10^{5} \times D^{*}\left(\mathrm{~cm}^{2} \cdot \mathrm{s}^{-1}\right)$ \\
\hline 1 & 3.33 & 7.21 \\
2 & 2.28 & 10.72 \\
3 & 1.67 & 16.70 \\
\hline
\end{tabular}

$[M C]=0.01 \mathrm{M}$, toluene phase and $T=298 \mathrm{~K}$.

mechanism for the facilitated transport of $\mathrm{Cr}(\mathrm{III})$ ions have been verified. The permeabilities and initial fluxes on the facilitated transport of these ions by this new SLM have been determined and are summarized in Table 4.

These results confirm that the macroscopic parameters $J_{0}$ and $P$ depend on the $\mathrm{Cr}(\mathrm{III})$ ions initial concentration and the Methyl Cholate is a better carrier than the Resorcinarene for the facilitated transport of these species ions from concentrated acidic media. The histogram in Figure 5 shows the evolution of permeability $P$ depending on the carrier and the source phase acidity.
From the data in Table 4, the plots $1 / J_{0}=f\left(1 / C_{0}\right)$ were drawn according to Equation (14), linear segments were obtained for the three studied acidities (Figure 6).

Slopes $(p)$ and intercepts $(O O)$ calculated from these linear segments, were used in the expressions of Equation (15), and the apparent diffusion coefficients $D^{*}$ and association constants $K_{\text {ass }}$ were determined at the three studied acidities. The obtained results, summarized in Table 5 confirm that the microscopic parameters $D^{*}$ and $K_{\text {ass }}$ are inversely correlated and that the association constant $K_{a s s}$ increases with acid concentration in the source phase.

The obtained values for these parameters $D^{*}$ and $K_{a s s}$, show that for this new SLM, stability and diffusion of the complex (TS) formed in the organic phase, are lower than those of the obtained complex for the previous SLM. This result clearly indicates that carrier nature is essential for better facilitated transport. The results for both studied

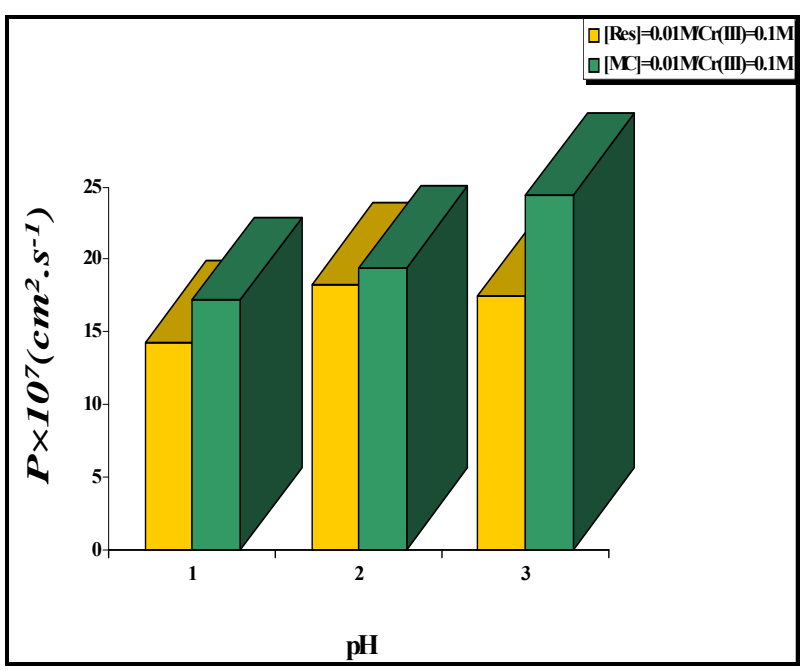

Figure 5. Evolution of the permeability parameter $\boldsymbol{P}$ depending on the carrier and the source phase acidity $[M C]=[\mathrm{RES}]=0.01 \mathrm{M},[\mathrm{Cr}(\mathrm{III})]=0.1 \mathrm{M}$ and $T=298^{\circ}$ K.

Table 4. Evolution of the parameters $P$ and $J_{0}$ with the source phase acidity.

\begin{tabular}{cccc}
\hline $\mathbf{p H}$ & $\boldsymbol{C}_{\mathbf{0}}=\left[\mathbf{C r}^{3+}\right]_{\mathbf{0}} \mathbf{M}$ & $\mathbf{1 0}^{\mathbf{7}} \times \mathbf{P}\left(\mathbf{c m}^{\mathbf{2}} \cdot \mathbf{s}^{-\mathbf{1}}\right)$ & $\begin{array}{c}\mathbf{1 0} \times \mathbf{J}_{\mathbf{0}} \\
\left(\mathbf{m m o l} \cdot \mathbf{c m}^{-2} \cdot \mathbf{s}^{-1}\right)\end{array}$ \\
\hline \multirow{2}{*}{$\mathbf{1}$} & $\mathbf{0 . 2 0}$ & $\mathbf{1 2 . 5 4 2}$ & $\mathbf{2 . 5 0 8}$ \\
& 0.10 & 14.292 & 1.430 \\
& 0.05 & 16.042 & 0.803 \\
$\mathbf{2}$ & $\mathbf{0 . 2 0}$ & $\mathbf{1 5 . 4 7 5}$ & $\mathbf{3 . 0 9 5}$ \\
& 0.10 & 18.310 & 1.831 \\
& 0.05 & 20.579 & 1.029 \\
$\mathbf{3}$ & $\mathbf{0 . 2 0}$ & $\mathbf{1 4 . 6 5 7}$ & $\mathbf{2 . 9 3 2}$ \\
& 0.10 & 17.500 & 1.750 \\
& 0.05 & 19.761 & 0.989 \\
\hline
\end{tabular}

[RES] $=0.01 \mathrm{M}$, toluene phase and $T=298 \mathrm{~K}$. 


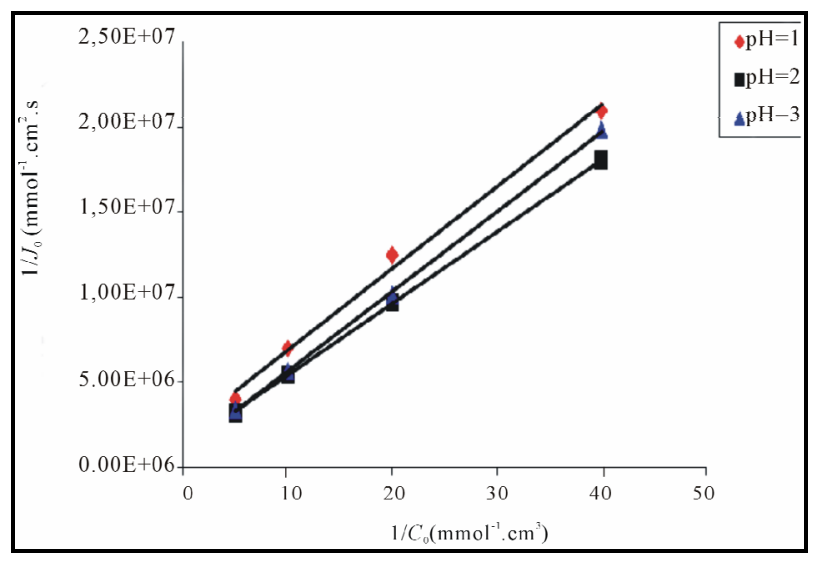

Figure 6. The Lineweaver-Burk plots for the transport of $\mathrm{Cr}$ (III) ions through the new SLM, $[$ RES $]=0.01 \mathrm{M}$, toluene phase and $T=298 \mathrm{~K}$.

Table 5. Evolution of the microscopic parameters $D^{*}$ and $K_{\text {ass }}$ with the source phase acidity.

\begin{tabular}{ccc}
\hline $\mathrm{pH}$ & $K_{\text {ass }}\left(\mathrm{L} \cdot \mathrm{mol}^{-1}\right)$ & $10^{5} \times D^{*}\left(\mathrm{~cm}^{2} \cdot \mathrm{s}^{-1}\right)$ \\
\hline 1 & 4.41 & 4.74 \\
2 & 2.87 & 8.29 \\
3 & 2.09 & 10.18 \\
\hline
\end{tabular}

[RES] $=0.01 \mathrm{M}$, toluene phase and $T=298 \mathrm{~K}$.

SLMs. show that this membrane type is very effective for the facilitated transport of $\mathrm{Cr}$ (III) ions, the carrier nature and the medium acidity, greatly influence the evolution of microscopic parameters $D^{*}$ and $K_{\text {ass }}$. The histogram in Figure 7, shows that there is a clear relationship between $K_{\text {ass }}$ and $D^{*}$, the methyl cholate agent is the best carrier and that the medium acidity is a determining factor for the facilitated transport and therefore the extraction of Cr(III) ions by SLMs.

On the other hand, high values of apparent diffusion coefficients $D^{*}$, indicate that the migration of the complex (Substrate-Carrier) through the organic phase is not a pure diffusion movement, and further studies are needed to elucidate the real movement of this complex through the SLM.

\subsection{Influence of the Medium Temperature}

To study the temperature influence on all parameters related to facilitated transport of this substrate through the (SLM)s, we performed the same experiments using the most efficient membrane in good conditions $[M C]=0.01 \mathrm{M}$ and $\mathrm{pH}=2$, The graph in Figure 8, shows the evolution of a few lines on the representation of the function $-\operatorname{Ln}\left(C_{0}-2 C_{r}\right)=f(t)$, for different studied temperatures, we find that the kinetic model established for the facilitated transport of $\mathrm{Cr}(\mathrm{III})$ ions, for which we consider the diffusion of substrate-carrier complex $(S T)$ is the rate determining step, is well verified for all tested temperatures.

The Table 6 includes all values of macroscopic parameters $P$ and $J_{0}$, determined for temperatures ranging from 288 to $303 \mathrm{~K}$. Data in this table show that the temperature factor is essential for the facilitated transport of substrates across these membranes type (SLM)s, and an increase in temperature from 288 to $303 \mathrm{~K}$, the permeability parameter has almost doubled.

This important influence of temperature is related certainly to increased reaction rates for formation and dissociation substrate-carrier complex $(S T)$, and therefore to decrease the stability of this complex in the SLM organic phase. To determine the influence of this factor on the evolution of parameters $K_{a s s}$ and $D^{*}$, we plotted the functions $1 / J_{0}=f\left(1 / C_{0}\right)$ (Equation 14), for various studied temperatures. The lines in Figure 9, clearly show that the

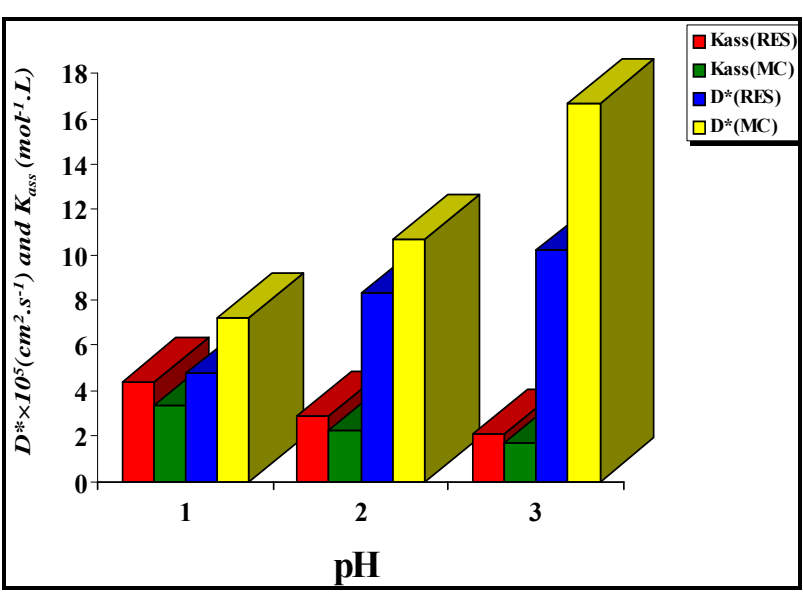

Figure 7. Evolution of the parameters $D^{*}$ and $K_{a s s}$ according to the medium acidity and the carrier nature, $[M C]=[$ RES $]=0.01 \mathrm{M}$ and $T=298^{\circ} \mathrm{K}$.

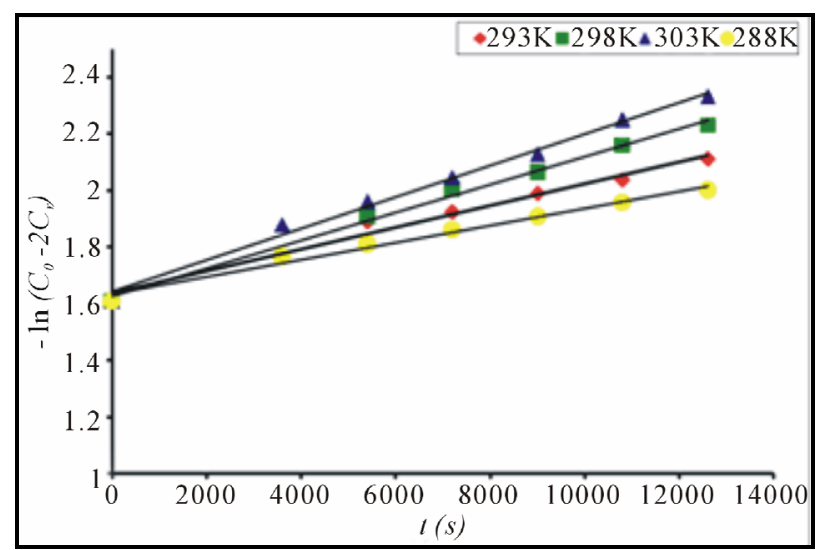

Figure 8. The temperature factor influence on the evolution of rights $-\operatorname{Ln}\left(C_{0}-2 C_{r}\right)=f(t)$, for the transport of $\mathrm{Cr}$ (III) ions, $[C M]=0.01 \mathrm{M}, \mathrm{pH}=2$ and $\left[\mathrm{Cr}^{3+}\right]=0.20 \mathrm{M}$. 
experimental results verified the proposed mechanism, there is a clear influence of temperature factor on the evolution of these microscopic parameters $K_{a s s}$ and $D^{*}$, and an increase in temperature resulted in a decreased of the substrate-carrier complex stability $\left(K_{a s s}\right)$, and consequently a large increase in the apparent diffusion coefficient $\left(D^{*}\right)$, concerning the movement of this complex through the SLM organic phase.

Slopes $(p)$ and intercepts $(O O)$ calculated from these linear segments, were used in the expressions of Equation (15), coefficients $D^{*}$ and association constants $K_{\text {ass }}$ were determined for all studied temperatures. Data in Table 7, confirm that the microscopic parameters $D^{*}$ and $K_{a s s}$ are inversely correlated and the association constant $K_{\text {ass }}$ decreases slightly when the temperature varies from 288 to $303 \mathrm{~K}$, whereas for the same variation of this factor (temperature), the apparent diffusion coefficients $D^{*}$ has doubled.

This important evolution of the apparent diffusion coefficient $D^{*}$ as a temperature function (Figure 10), and the activation parameters values determined in subsequent experiments, allow to specify the movement nature of the substrate through the SLM organic phase, and to explain the high permeability of such membranes for facilitated transport of these ions. Indeed these activation parameters values are related to the formation-dissociation equilibrium on the substrate-carrier complex $(S T)$, at the interfaces and within the organic phase of the studied SLM.

\subsection{Experimental Determination of Activation Parameters}

The flux of ions transport in liquid membranes is dependent on numerous factors that are associated with the experimental conditions (temperature of membrane phase, carrier concentration, $\mathrm{pH}$, and metal concentration in source phase...). Under the same experimental conditions of the source and receiving aqueous phases and the membrane $\left([C M]=0.01 \mathrm{M} . \mathrm{pH}=2\right.$ and $[\mathrm{Cr}(\mathrm{III})]_{0}=$ $0.20 \mathrm{M}$ ), metal ion flux for the facilitated transport is dependent only on temperature. However, recent studies [35-37] have shown that the measurement of the initial transport flux at different temperatures enables calculation of the activation energy from the Arrhenius equation according to the following expression (Equation 17):

$$
\ln J_{i}=(-E a / R T) \times 1 / T+\ln A_{j}
$$

where, $E a$ is the activation energy (given in units of $\left.\mathrm{kJ} \cdot \mathrm{mol}^{-1}\right), R$ the gas constant $\left(8.314 \mathrm{~J} \cdot \mathrm{mol}^{-1} \cdot \mathrm{K}^{-1}\right)$, and $A_{j}$ a constant. The all results obtained for temperatures 288 , 293, 298 and $303 \mathrm{~K}$ are shown in Table $\mathbf{6}$ and are depicted graphically in Figure 11.

As the data given in Table 6 show, the parameters $P$ and $J_{0}$ on facilitated transport of $\mathrm{Cr}$ (III) ions are strongly dependent on temperature. Indeed, these results show that the variation of the temperature factor causes a large change in values of initial fluxes, the graph in Figure 11 shows that this flux decreases linearly with the higher inverse of temperature; this fact is confirmed by the very high determination coefficient $\left(r^{2}=0.99\right)$. Therefore, in accordance with Equation (17), the activation energy may be determined if the slope of the straight line for the function $\ln J_{0}=F(1 / T)$ is known. The activation energy determined in the temperature range $288^{\circ}-303^{\circ} \mathrm{K}$ is $E a=30.74 \mathrm{~kJ} \cdot \mathrm{mol}^{-1}$ and the constant term $A_{j}=44.71$ $\mathrm{mol} \cdot \mathrm{m}^{-2} \cdot \mathrm{s}^{-1}$. It is known that the membrane process for the facilitated transport through the SLM is controlled by diffusion of substrate-carrier complex $(S T)$ through the membrane, and does not depend on reactions that occur at interfaces (aqueous phases/membrane). The flux on the transport of $\mathrm{Cr}$ (III) ions through this studied SLM, increased with a higher temperature, therefore, this proc-

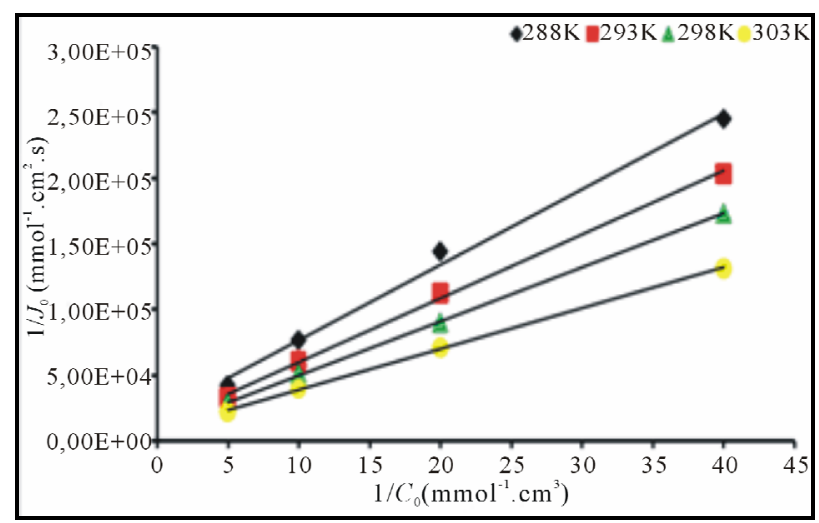

Figure 9. The temperature influence on the evolution of Lineweaver-Burk plots for $\mathrm{Cr}$ (III) ions transport. $[M C]=0.01 \mathrm{M}$, $\mathrm{pH}=2$ and $\left[\mathrm{Cr}^{3+}\right]_{0}=0.20 \mathrm{M}$.

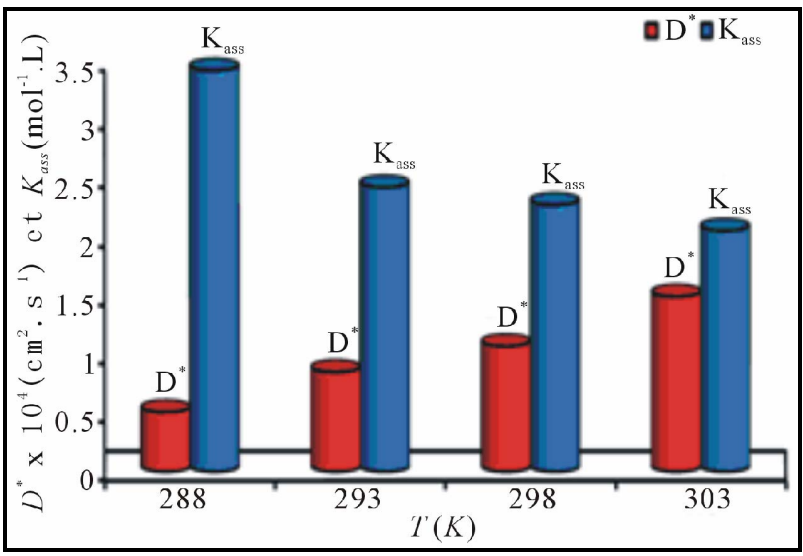

Figure 10. Evolution of the microscopic parameters $D^{*}$ and $K_{\text {ass }}$ according to the medium temperature $[C M]=0.01 \mathrm{M}$, $\mathbf{p H}=2$ and $[\mathrm{Cr}(\mathrm{III})]_{0}=0.20 \mathrm{M}$. 
Table 6. Temperature effect on the macroscopic parameters for the facilitated transport of $\mathrm{Cr}$ (III) ions.

\begin{tabular}{|c|c|c|c|}
\hline$T\left({ }^{\circ} \mathbf{K}\right)$ & $C_{0}=\left[\mathbf{C r}^{3+}\right]_{0} M$ & $\begin{array}{c}P \times 10^{7} \\
\left(\mathrm{~cm}^{2} \cdot \mathrm{s}^{-1}\right)\end{array}$ & $\begin{array}{c}J_{0} \times 10^{5} \\
\left(\mathrm{mmol} \cdot \mathrm{cm}^{-2} \cdot \mathrm{s}^{-1}\right)\end{array}$ \\
\hline \multirow[t]{4}{*}{288} & 0.20 & 11.67 & 2.34 \\
\hline & 0.10 & 12.98 & 1.30 \\
\hline & 0.05 & 13.86 & 0.70 \\
\hline & 0.025 & 16.32 & 0.41 \\
\hline \multirow[t]{4}{*}{293} & 0.20 & 15.02 & 3.01 \\
\hline & 0.10 & 16.48 & 1.65 \\
\hline & 0.05 & 17.72 & 0.89 \\
\hline & 0.025 & 19.62 & 0.47 \\
\hline \multirow[t]{4}{*}{298} & 0.20 & 16.92 & 3.39 \\
\hline & 0.10 & 19.47 & 1.95 \\
\hline & 0.05 & 22.17 & 1.11 \\
\hline & 0.025 & 23.05 & 0.58 \\
\hline \multirow[t]{4}{*}{303} & 0.20 & 22.46 & 4.50 \\
\hline & 0.10 & 24.94 & 2.50 \\
\hline & 0.05 & 28.08 & 1.41 \\
\hline & 0.025 & 29.32 & 0.72 \\
\hline
\end{tabular}

$[M C]=0.01 \mathrm{M}$, toluene phase and $\mathrm{pH}=2$.

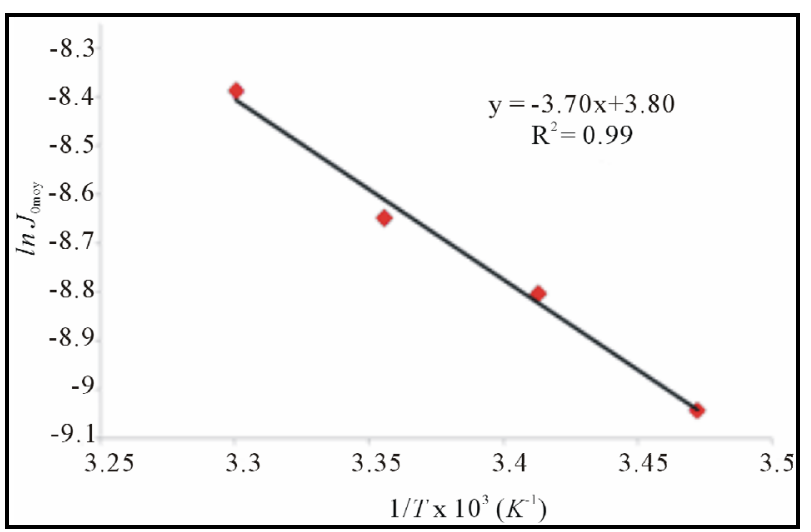

Figure 11. Dependence of $\mathrm{Cr}$ (III) ions fluxes on temperature in facilitated transport across the SLM. $[C M]=0.01 \mathrm{M}, \mathrm{pH}$ $=2$ and $\left[\mathrm{Cr}^{3+}\right]_{0}=0.20 \mathrm{M}$.

ess is controlled by the diffusion kinetics. To complete our results, we calculated the activation parameters $\Delta H^{\#}$ and $\Delta S^{\#}$, related to the activation energy $E a$ and the constant $A_{i}$, by the relations of Equations (18) and (19).

$$
\begin{aligned}
& \Delta H^{\#}=E a-2500=+28.26 \mathrm{~kJ} \cdot \mathrm{mol}^{-1} \text { and } \\
& \Delta S^{\#}=R\left(\ln A_{j}-30.46\right)=-221.55 \mathrm{~J} \cdot \mathrm{mol}^{-1} \cdot \mathrm{K}^{-1} \text { at } 298^{\circ} \mathrm{K}
\end{aligned}
$$

These low values $E a$ and $\Delta H^{\#}$, indicate that the transition
Table 7. Temperature influence on the parameters $D^{*}$ and $K_{\text {ass }}$ for $\mathrm{Cr}(\mathrm{III})$ ions transport.

\begin{tabular}{ccc}
\hline $\mathrm{T}\left({ }^{\circ} \mathrm{K}\right)$ & $\mathrm{D}^{*} \cdot 10^{5}\left(\mathrm{~cm}^{2} \cdot \mathrm{s}^{-1}\right)$ & $\mathrm{K}_{\text {ass }}\left(\mathrm{L} \cdot \mathrm{mol}^{-1}\right)$ \\
\hline 288 & 5.08 & 3.43 \\
293 & 8.51 & 2.43 \\
298 & 10.72 & 2.28 \\
303 & 14.96 & 2.06 \\
\hline
\end{tabular}

$[M C]=0.01 \mathrm{M}$, toluene phase and $\mathrm{pH}=2$.

state on the reaction formation-dissociation of the complex $(S T)$ requires little energy, while a negative value of $\Delta S^{\#}$ expresses a gain of order and therefore a real association between substrate and the carrier in this transition state. All results for the facilitated transport of $\mathrm{Cr}(\mathrm{III})$ ions, by theses prepared SLMs, especially the very high values of apparent diffusion coefficients $\left(D^{*}\right)$ and the low value of the activation energy $E a$, clearly indicate that the substrate movement within the membrane is not a simple diffusion phenomenon, controlled by a concentration gradient at the SLM interfaces. Therefore, the movement associated with the passage of the substrate through the SLM, is in a series of reactions (formation/ dissociation), and by successive jumps of the substrate from one carrier to another. Various studies [34,38], show that the supported liquid membranes are very effective for the facilitated transport of some organic compounds (sugars, organic acids) and can be fully operational for the separation of these compound mixtures. Indeed, the parameters $K_{a s s}$ and $D^{*}$, evolve in reverse and we see that very low values of the constant $K_{\text {ass }}$, correspond to high values of apparent coefficients $D^{*}$, this important result shows that these high values of the coefficients $D^{*}$ do not certainly reflect a pure diffusion movement of the complex (ST) through the SLM organic phase. On the other hand, recent studies [39-41] for the facilitated transport of metal ions or organic molecules by this type of membranes, clearly confirm this high values of the coefficients $D^{*}$ and explain this result by the movement nature of the substrate S through SLM organic phase during its migration from source phase to receiving phase.

\section{Conclusion}

Two supported liquid membranes (SLM) are prepared with the same polymer support (PVDF), the same organic phase (toluene) and two different carriers (Methyl Cholate and Resorcinarene), these two membranes are used to the facilitated transport of $\mathrm{Cr}(\mathrm{III})$ ions from concentrated acidic environments. The experimental results verify the proposed kinetic model, which is used to determine the macroscopic parameters, permeabilities $P$ 
and the initial fluxes $J_{0}$ for both prepared membranes (SLM). The results show that the used SLM are very permeable, and can perform the facilitated transport of $\mathrm{Cr}(\mathrm{III})$ ions, with large fluxes. To understand this phenomenon facilitated transport of substrates through these liquid membrane types, we develop a mechanism based on the formation by interaction of an entity substratecarrier at the interface membrane source phase, and the migration of this formed entity through the SLM organic phase. This mechanism has been verified, it is used to determine the microscopic parameters, association constant $K_{\text {ass }}$ and apparent diffusion coefficient $D^{*}$, related to the formation of complex $(S T)$, and its diffusion through the SLM. The low values of the constants $K_{\text {ass }}$ and large values of the coefficients $D^{*}$ determined, may explain the significant permeabilities and large fluxes, obtain for the facilitated transport of $\mathrm{Cr}$ (III) ions by this supported liquid membranes type. Changing values for the parameters $K_{\text {ass }}$ and $D^{*}$, clearly indicate that the stability and the diffusion of the substrate carrier complex $(S T)$ are closely related to the movement nature of the substrate in the SLM organic phase. The study of the temperature factor influence, shows a clear evolution of these parameters, and an increase in the source phase temperature, leads to an increase of the coefficients $D^{*}$, so the constants $K_{\text {ass }}$ lower, and therefore a membrane more permeable to large fluxes. This study has identified the activation parameters $\left(E a, \Delta H^{\#}\right.$ and $\left.\Delta S^{\#}\right)$, that characterize the formation and the dissociation reactions of the complex $(S T)$ at interfaces. The obtained values confirm the high permeability of the studied membranes and allow the determination of the mechanism type of the substrate movement through the organic phase of the membrane. The overall results show that the agent Methyl Cholate is a suitable carrier for the preparation of highly permeable SLMs, for facilitated extraction of chromium ions.

\section{Acknowledgements}

All authors thank the Agence Universitaire de la Francophonie (AUF) for financial support (PCSI 59113PS 014), and Professor Jean-François Verchère from the University of Rouen (France) for his advice, fruitful discussions, strong encouragement and exemplary cooperation.

\section{REFERENCES}

[1] M. A. Chaudry, N. Bukhari, M. Mazhar and W. Abbasi, "Coupled Transport of Chromium(III) Ions across Triethanolamine/Cyclohexanone Based Supported Liquid Membranes for Tannery Waste Treatment," Separation and Purification Technology, Vol. 55, No. 3, 2007, pp. 292-299. doi:10.1016/j.seppur.2006.12.008
[2] S. Biswas, P. N. Pathak and S. B. Roy, "Carrier Facilitated Transport of Uranium across Supported Liquid Membrane Using Dinonyl Phenyl Phosphoric Acid and Its Mixture with Neutral Donors," Desalination, Vol. 290, 2012, pp. 74-82. doi:10.1016/j.desal.2012.01.006

[3] S. ur Rehman, G. Akhtar, M. A. Chaudry, K. Ali and N. Ullah, "Transport of $\mathrm{Ag}^{+}$through Tri-n Dodecylamine Supported Liquid Membranes," Journal of Membrane Science, Vol. 389, 2012, pp. 287-293.

doi:10.1016/j.memsci.2011.10.040

[4] M. Hor, A. Riad, A. Benjjar, L. Lebrun and M. Hlaïbi, "Technique of Supported Liquid Membranes (SLMs) for the Facilitated Transport of Vanadium Ions $\left(\mathrm{VO}_{2}^{+}\right): \mathrm{Pa}-$ rameters and Mechanism on the Transport Process," Desalination, Vol. 255, No. 1-3, 2010, pp. 188-195. doi:10.1016/j.desal.2009.12.023

[5] H. Hassoune, T. Rhlalou, M. A. Frouji, C. Chappey and J.-F. Verchère, "Application of Supported Liquid Membranes Containing Methyl Cholate in Cyclohexane for the Carrier-Mediated Transport of Sugars," Desalination, No. 1-3, Vol. 189, 2006, pp. 31-42. doi:10.1016/j.desal.2005.06.010

[6] K. Touaj, N. Tbeur, M. Hor, J. F. Verchère and M. Hlaïbi., "A Supported Liquid Membrane (SLM) with Resorcinarene for Facilitated Transport of Methyl Glycopyranosides: Parameters and Mechanism Relating to the Transport," Journal of Membrane Science, Vol. 337, No. 1-2, 2009, pp. 28-38. doi:10.1016/j.memsci.2009.03.014

[7] R. K. Biswas and M. A. Hayat, "Solvent Extraction of Zirconium (IV) from Chloride Medium by D2EHPA in Kerosene," Hydrometallurgy, Vol. 63, No. 2, 2002, pp. 149-158. doi:10.1016/S0304-386X(01)00220-1

[8] R. K. Biswas and M. A. Hayat, "Kinetics of Solvent Extraction of Zirconium (IV) from Chloride Medium by D2EHPA in Kerosene Using the Single Drop Technique," Hydrometallurgy, Vol. 65, No. 2-3, 2002, pp. 205-216. doi:10.1016/S0304-386X(02)00089-0

[9] J.-H. Chen, Y.-Y. Kao and C.-H. Lin, "Selective Separation of Vanadium from Molybdenum, Using D2EHPAImmobilized Amberlite XAD-4 Resin," Separation Science and Technology, Vol. 38, No. 15, 2003, pp. $3827-$ 3852. doi:10.1081/SS-120024234

[10] G. Jia, G Torri and M. Ptruzzi, "Distribution Coefficients of POLONIUM between 5\% Topo in Toluene and Aqueous Hydrochloric and Nitric Acids," Applied Radiation and Isotopes, Vol. 61, No. 2-3, 2004, pp. 279-282. doi:10.1016/j.apradiso.2004.03.021

[11] W. F. van Straate-Nijenhuis, F. deJong and D. N. Reinhoudt, "Macrocyclic Carriers in Supported Liquid Membranes," Recueil des Travaux Chimiques des Pays-Bas, Vol. 112, No. 6, 1993, pp. 317-324. doi:10.1002/recl.19931120602

[12] L. Boyadzhiez and G. Kyuchouv, "Short Communication: Further Development of Carrier-Mediated Extraction," Journal of Membrane Science, Vol. 6, 1980, pp. 107-202.

[13] H. C. Visser, D. N. Reinhoudt and F. de Jong, "CarrierMediated Transport through Liquid Membranes," Chemical Society Reviews, Vol. 23, No. 2, 1994, pp. 75-81. doi:10.1039/cs9942300075 
[14] L. Zhao, D. Fei, Y. Dang, X. Zhou and J. Xiao, "Studies on the Extraction of Chromium(III) by Emulsion Liquid Membrane," Journal of Hazardous Materials, Vol. 178, No. 1-3, 2010, pp. 130-135. doi:10.1016/j.jhazmat.2010.01.052

[15] R. M. Izatt, J. D. Lamb and R. L. Brueing, "Comparison of Bulk, Emulsion, Thin Sheet Supported, and Hollo fiber SLM, in Macrocycle-Mediated Cation Separations," Separation Science and Technology, Vol. 23, No. 12-13, 1988, pp. 1645-1685. doi:10.1080/01496398808075654

[16] Y. M. Scindia, A. K. Pandey and A. V. R. Reddy, "Coupled-Diffusion Transport of $\mathrm{Cr}(\mathrm{VI})$ across Anion-Exchange Membranes Prepared by Physical and Chemical Immobilization Methods," Journal of Membrane Science, Vol. 249, No. 1-2, 2005, pp. 143-152. doi:10.1016/i.memsci.2004.10.015

[17] M. Mulder, "Basic Principles in Membrane Technology," Kluwer Academic Publishers, Dordrecht, 1991. doi:10.1007/978-94-017-0835-7

[18] J. A. Jönsson and L. Mathiasson," Liquid Membrane Extraction in Analytical Sample Preparation," Trends in Analytical Chemistry, Vol. 18, No. 5, 1999, pp. 318-325. doi:10.1016/S0165-9936(99)00102-8

[19] H. Singh, S. L. Mishra and R. Vijayalakshmi, "Uranium Recovery from Phosphoric Acid by Solvent Extraction Using a Synergistic Mixture of Di-Nonyl Phenyl Phosphoric Acid and Tri-n-Butyl Phosphate," Hydrometallurgy, Vol. 73, No. 1-2, 2004, pp. 63-70. doi:10.1016/j.hydromet.2003.08.006

[20] T. Yamaguchi, K. Nishimura, T. Shinbo and M. Sugiura, "Amino Acid Transport through Supported Liquid Membrane: Mechanism and Its Application to Enantiomeric Resolution," Bioelectrochemistry and Bioenergetics, Vol. 20, No. 1-3, 1988, pp. 109-123. doi:10.1016/S0302-4598(98)80009-3

[21] P. Dzygiel, P. Wieczorek, J. A. Jönsson and L. Mathiasson, "Enrichment of Amino Acids by Supported Liquid Membrane Extraction Using Aliquat 336 as a Carrier," Analytical Letters, Vol. 31, No. 7, 1998, pp. 1261-1274. doi:10.1080/00032719808002861

[22] M. Rak, P. Dzygiel and P. Wieczorek, "Supported Liquid Membrane Extraction of Aromatic Aminophosphonates," Analytica Chimica Acta, Vol. 433, No. 2, 2001, pp. 227236. doi:10.1016/S0003-2670(01)00785-1

[23] M. Di Luccio, B. D. Smith, T. Kida, T. L. M. Alves and C. P. Borges, "Evaluation of flat Sheet and Hollow Fiber Supported Liquid Membranes for Fructose Pertraction from a Mixtures of Sugars," Desalination, Vol. 148, No. 1-3, 2002, pp. 213-220. doi:10.1016/S0011-9164(02)00700-2

[24] N. Tbeur, T. Rhlalou, M. Hlaïbi, D. Langevin, M. Métayer and J. F. Verchère, "Selective Transport of Alditols through a Supported Liquid Membrane," Carbohydrate Research, Vol. 329, No. 2, 2000, pp. 409-422. doi:10.1016/S0008-6215(00)00188-9

[25] M. Hlaïbi, N. Tbeura, A. Benjjar, O. Kamal and L. Lebrun, "Carbohydrate-Resorcinarene Complexes Involved in the Facilitated Transport of Alditols Across a Supported Liquid Membrane," Journal of Membrane Science,
Vol. 377, No. 1-2, 2011, pp. 231-240. doi:10.1016/j.memsci.2011.04.055

[26] P. Dzygiel and P. Wieczorek, "Extraction of glyphosate by a Supported Liquid Membrane Technique," Journal of Chromatography A, Vol. 889, No. 1-2, 2000, pp. 93-98. doi:10.1016/S0021-9673(00)00120-5

[27] M. Mulugeta and N. Megersa, "Carrier-Mediated Extraction of Bipyridilium Herbicides across the Hydrophobic Liquid Membrane," Talanta, Vol. 64, No. 1, 2004, pp. 101-108. doi:10.1016/j.talanta.2003.11.049

[28] S. Glasstone, K. J. Laidler and H. Eyring, "The Theory of Rate Processes," McGraw-Hill, New York, 1941.

[29] C. Fontàs, R. Tayeb, M. Dhahbi, E. Gaudichet, F. Thominette, P. Roy, K. Steenkeste, M.-P. Fontaine-Aupart, S. Tingry, E. Tronel-Peyroz and P. Seta, "Polymer Inclusion Membranes: The Concept of Fixed Sites Membrane Revised," Journal of Membrane Science, Vol. 290, No. 1-2, 2007, pp. 62-72. doi:10.1016/j.memsci.2006.12.019

[30] J. Konczyk, C. Kozlowski and W. Walkowiak, "Removal of Chromium(III) from Acidic Aqueous Solution By Polymer Inclusion Membranes with D2EHPA and Aliquat 336," Desalination, Vol. 263, No. 1-3, 2010, pp. 212-216. doi:10.1016/i.desal.2010.06.061

[31] A. Lewis and J. Azoro, "The Nature of the Intermediate Formed in the Methoxymercuration of p-Substituted Styrenes," Tetrahedron Letters, Vol. 20, No. 38, 1979, pp. 3627-3630. doi:10.1016/S0040-4039(01)95481-4

[32] M. F. Ruasse, A. Argile and J. E. Dubois, "The Multipathway Mechanism in Styrene bromination: Competition between Bromonium and Carbonium Ion intermediates," Journal of the American Chemical Society, Vol. 100, No. 24, 1978, pp. 7645-7652. doi:10.1021/ja00492a035

[33] R. S. Juang and L. J. Chen, "Transport of Citric Acid across a SLM Containing Various Salts of a Tertiary Amine," Journal of Membrane Science, Vol. 123, No. 1, 1997, pp. 81-87. doi:10.1016/S0376-7388(96)00205-0

[34] E. Miyako, T. Maruyama, N. Kamiya and M. Goto, "Transport of Organic Acids through a Supported Liquid Membrane Driven by Lipase-Catalyzed Reactions," Journal of Bioscience and Bioengineering, Vol. 96, No. 4, 2003, pp. 370-374.

[35] S. P. Kusumocahyo, T. Kanamori, K. Sumaru, S. Aomatsu, H. Matsuyama, M. Teramoto and T. Shinbo, "Development of Polymer Inclusion Membranes Based on Cellulose Triacetate: Carrier-Mediated Transport of Cerium(III)," Journal of Membrane Science, Vol. 244, No. $1-2,2004$, pp. 251-257. doi:10.1016/j.memsci.2004.07.013

[36] A. Yilmaz, A. Kaya, H. Korkmaz Alpoguz, M. Ersoz and M. Yilmaz, "Kinetic Analysis of Chromium(VI) Ions Transport through a Bulk Liquid Membrane Containing p-Tert-Butylcalix[4]Arene Dioxaoctylamide Derivative," Separation and Purification Technology, Vol. 59, No. 1, 2008, pp. 1-8. doi:10.1016/j.seppur.2007.05.017

[37] C. A. Kozłowski, "Kinetics of Chromium(VI) Transport from Mineral Acids across Cellulose Triacetate (CTA) Plasticized Membranes Immobilized by Tri-n-Octylamine," Industrial \& Engineering Chemistry Research, Vol. 46, No. 16, 2007, pp. 5420-5428. 
doi:10.1021/ie070215i

[38] R. S. Juang, R. H. Huang and R. T. Wu, "Separation of Citric and Lactic Acids in Aqueous Solutions by Solvent Extraction and Liquid Membrane Processes," Journal of Membrane Science, Vol. 136, No. 1-2, 1997, pp. 89-99. doi:10.1016/S0376-7388(97)00176-2

[39] F. J. Alguacil and H. Tayibi, "Carrier-Facilitated Transport of Cd(II) from a High-Salinity Chloride Medium across a Supported Liquid Membrane Containing Cyanex 923 in Solvesso 100," Hydrometallurgy, Vol. 180, No. 13, 2005, pp. 181-187.

[40] G. O. Yahaya, B. J. Brisdon and R. England, "Facilitated
Transport of Lactic Acid and Its Ethyl Ester by SLMs Containing Functionalized Polyorganosiloxanes as Carriers," Journal of Membrane Science, Vol. 168, No. 1-2, 2000, pp. 187-201. doi:10.1016/S0376-7388(99)00312-9

[41] H. Hassoune, T. Rhlalou, M. Métayer and J. F. Verchère, "Facilitated Transport of Aldoses by Methyl Cholate through SLMs Impregnated with Various Solvents," Journal of Membrane Science, Vol. 248, No. 1-2, 2005, pp. 89-98. doi:10.1016/j.memsci.2004.08.024

\section{Nomenclature}

a: slope of the plot $-\operatorname{Ln}\left(C_{0}-2 C_{r}\right)=f(t)$.

$C_{0}$ : initial concentration of $\mathrm{Cr}(\mathrm{III})$ ions in the feed phase $\left.\mathrm{mol} \cdot \mathrm{L}^{-1}\right)$.

$C_{r}$ : concentration of transported $\mathrm{Cr}(\mathrm{III})$ ions in the receiving phase $\left(\mathrm{mol} \cdot \mathrm{L}^{-1}\right)$.

$C_{F}$ : concentration of $\mathrm{Cr}(\mathrm{III})$ ions in the feed phase $\left(\mathrm{mol} \cdot \mathrm{L}^{-1}\right)$.

$\boldsymbol{P}$ : the permeability of the SLM for Cr(III) ions $\left(\mathrm{cm}^{2} \cdot \mathrm{s}^{-1}\right)$.

$J_{0}\left(\right.$ or $\left.\boldsymbol{J}_{i}\right)$ : initial flux on the facilitated transport of substrate $\left(\mathrm{mmol} \cdot \mathrm{cm}^{-2} \cdot \mathrm{s}^{-1}\right)$.

$D^{*}$ : apparent diffusion coefficient of the complex (TS) $\left(\mathrm{cm}^{2} \cdot \mathrm{s}^{-1}\right)$.

$K_{\text {ass: }}$ association constant on the formation of the complex (TS) $\left(\mathrm{L} \cdot \mathrm{mol}^{-1}\right)$.

I: the membrane thickness ( $\mathrm{mm}$ or $\mu \mathrm{m})$.

$S$ : the membrane area $\left(\mathrm{cm}^{2}\right)$.

$[\boldsymbol{T}]_{0}$ : concentration of carrier in the membrane $\left(\mathrm{mol} \cdot \mathrm{L}^{-1}\right)$.

$\left[\right.$ TS ]: concentration of the complex in the organic phase $\left(\mathrm{mol} \cdot \mathrm{L}^{-1}\right)$.

$T$ : temperature $\left(\mathrm{K}\right.$ or $\left.{ }^{\circ} \mathrm{C}\right)$.

$t$ : time (s).

$\boldsymbol{V}$ : volume of the receiving compartment $\left(\mathrm{cm}^{3}\right)$. 